\title{
XRF Technique for the Evaluation of Gum Arabic Bonded Rhizophora spp. Particleboards as Tissue Equivalent Material
}

\author{
Ali Abuarra, Sabar Bauk, Rokiah Hashim, Sivamany Kandaiya, Ehsan Taghizadeh Tousi, and Baker \\ Ababneh
}

\begin{abstract}
For the first time, Gum Arabic (GA) is used as a binder in particleboards preparation and the attenuation properties of the fabricated particleboards were evaluated to check their suitability as tissue equivalent material. Gum Arabic was added into Rhizophora spp. particleboards of four particle sizes at three different $G A$ adhesive levels. The $X$-ray fluorescence (XRF) technique was used to measure the linear and the mass attenuation coefficients of the fabricated particleboards at effective energy range of $17.4-26.7 \mathrm{keV}$. This was achieved by determining the attenuation of $\mathrm{K \alpha 1} \mathrm{X}$-ray fluorescent (XRF) photons from niobium, molybdenum, palladium, silver and tin targets. The results were compared with theoretical values of water calculated using XCOM computer program. The mass attenuation coefficients of the GA bonded Rhizophora spp. particleboards were found to be close to the values of water calculated in XCOM at the same photon energies. Luckily, fabricated particleboards showed tissue equivalent results which optimistically can open a new window on the consumption of such a natural adhesive in particleboards as phantom material in dosimetric phantoms and quality control applications.
\end{abstract}

Index Terms-Attenuation coefficients, gum arabic, particleboards, Rhizophora spp, X-ray flourescence.

\section{INTRODUCTION}

Since the eighties, considerable effort has been employed in the evaluation and characterization of photon attenuation for a wide range of materials [1]. The mass attenuation coefficient of various elements and compounds of biological and dosimetric materials have been treated by some authors, but, many of the so-called tissue equivalent materials fail to provide a good agreement to the mass attenuation coefficient of water at low and high energies [2]. Worth of notice are the efforts made by many other workers in characterizing photon attenuation for wood. For example, considerable research is being focused on the suitability of the mangrove hardwood

Manuscript received February 27, 2014; revised April 27, 2014. This work was supported in part by research university grant 1001/pfizik/846085 from Universiti Sains Malaysia.

A. Abuarra, Sivamany Kandaiya, E. T. Tousi, and B. Ababneh are with the Medical Physics Department, School of Physics, Universiti Sains Malaysia, 11800 Penang, Malaysia (Corresponding author: A. Abuarra; e-mail: aliom@yahoo.com, lan@usm.my, ehsan.tousi@yahoo.com, baker773@yahoo.com).

S. Bauk is with the Physics Section, School of Distance Education, Universiti Sains Malaysia, 11800 Penang, Malaysia (e-mail: sabar@usm.my).

R. Hashim is with the Division of Bioresource, Paper and Coatings Technology, School of Industrial Technology, Universiti Sains Malaysia, 11800 Minden, Penang, Malaysia (e-mail: hrokiah1@gmail.com).
Rhizophora spp. as tissue equivalent phantom material [2]-[8].

According to the previous reports of the Rhizophora spp. attenuation properties, particleboards are found better than the raw wood [7]. Despite, binderless particleboards showed good agreement in dosimetric properties with other standard phantom materials in radiation dosimetry, it still not very strong especially in case of internal bond strength and dimensional stability [2]. Moreover, using synthetic binders is to be avoided due to the harmful emissions that threaten health and environment. Therefore, using gum Arabic in this study as a binder in particleboard manufacture might be a suitable substitute to the currently available binders.

In this study, the Rhizophora spp. barks and GA are used for the particleboards fabrication. Three different particle sizes of the Rhizophora spp. with four GA percentage levels are utilized. The X-ray fluorescence (XRF) technique is used to measure the linear and mass attenuation coefficients of the fabricated particleboards at effective energy range of 17.4-26.7 $\mathrm{keV}$ and the results will be compared to the calculated values of water which is often considered as the perfect match for soft-tissue. The attenuation properties of the fabricated particleboards were studied to evaluate their potential as phantom material.

\section{MAtERIALS AND MethodS}

\section{A. Rhizophora spp. Particleboards}

The Rhizophora spp. trunks were obtained from Kuala Sepatang, Perak, Malaysia. The wood particles were prepared based on Shakhreet et al. [8] study with some modifications. The Rhizophora spp. trunks were cut into smaller pieces before they were reduced to smaller size by using a surface planner machine (Holy Tek-HP 20, Taiwan). Then, the Rhizophora spp. particles were further ground using a grinder machine (Tai-yi model, Retch, Germany), and the last step was repeated for many times to get different particle sizes. After that, a horizontal screening machine with three sieves opening of $210 \mu \mathrm{m}, 149 \mu \mathrm{m}$ and $74 \mu \mathrm{m}$ was used to classify the particles according to the particle size into three samples denoted as A, B, and C. Arabic gum powder was also sieved and found to have a size of less than $149 \mu \mathrm{m}$.

The GA powder was sprayed onto preweighed quantities of dried Rhizophora spp. wood particles in a container with relative percentages of $0 \%, 5 \%, 10 \%$, and $15 \%(\mathrm{w} / \mathrm{w})$ based on oven dried particles weight. Twenty percent $(\mathrm{v} / \mathrm{w})$ of distilled water was added. The mixture was then spreaded 
uniformly on a square shape stainless steel plate and bounded with a square stainless steel frame $\left(21 \times 21 \mathrm{~cm}^{2}\right)$ and deckle. The mat was then cold-pressed at $8 \mathrm{~kg} / \mathrm{cm}^{2}$ pressure for about $3 \mathrm{~min}$ before hot-pressing at $210^{\circ} \mathrm{C}$. The mat was then pressed to the required thickness of $0.5 \mathrm{~cm}$ for $7 \mathrm{~min}$. The The boards were then conditioned in an environment of $(70+$ $5) \%$ relative humidity $(\mathrm{RH})$ and $28+2 \mathrm{oC}$ before being cut into test specimens and left to cool down. Then, the manufactured particleboard were removed from the frame, trimmed, and cut into $5 \mathrm{~cm} \times 5 \mathrm{~cm}$ pieces.

\section{B. Determination of the Linear and the Mass Attenuation Coefficients of GA and Particleboard Samples}

The mass attenuation coefficients of the GA and the fabricated Rhizophora spp. particleboards were determined by measuring the transmission of the X-ray fluorescent photons through samples of known thickness. The linear attenuation coefficients of all the particleboard samples were determined based on Marashdeh et al. [2] set up. The experimental set up in the present work is shown in Fig. 1.

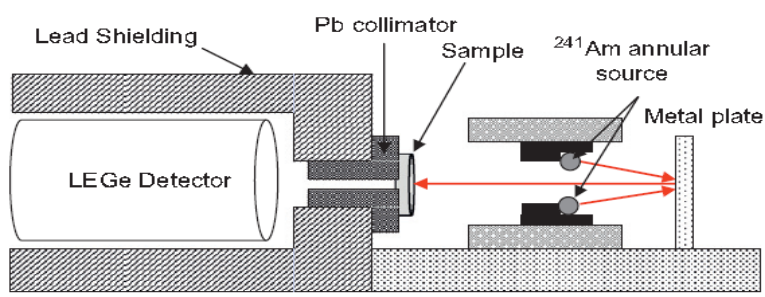

Fig. 1. The experimental set up for the measurement of the linear attenuation coefficients of GA treated Rhizophora spp. particleboards using X-ray fluorescence (XRF) beam (Marashdeh et al., 2012).

$5.0 \times 5.0 \mathrm{~cm} 2$ GA treated Rhizophora spp. samples were irradiated with XRF photon energies. Pure GA samples were prepared in button or disc shape with $1.35 \mathrm{~cm}$ diameter and $0.25,0.41,0.58$, and $0.76 \mathrm{~cm}$ thicknesses. Three readings were taken for each sample and the average value of the mass attenuation coefficient of each sample was determined. A $59.5 \mathrm{keV} \gamma$-ray of a $100 \mathrm{mCi} 241 \mathrm{Am}$ annular radioactive source was used to irradiate high- purity metal targets to produce the $\mathrm{x}$-ray fluorescence (XRF) photons. The five metal targets used in this study were Niobium $(\mathrm{Nb})$, Molybdenum (Mo), Palladium (Pd), Silver (Ag) and Tin (Sn) producing $\mathrm{K} \alpha 1$ fluorescent $\mathrm{X}$-rays with effective energies of $17.4,18.5,22.4,23.5$ and $26.7 \mathrm{keV}$, respectively.

The energy intensities were measured using a Low-Energy Germanium (LEGe) detector with an active area and diameter of $200 \mathrm{~mm} 2$ and $16 \mathrm{~mm}$, respectively. The crystal is $1.0 \mathrm{~cm}$ thick with a resolution (FWHM) of $400 \mathrm{eV}$ at the $241 \mathrm{Am} 60 \mathrm{keV}$ emission line. The signals were collected into a spectroscopy amplifier and multichannel analyzer. To reduce background and scattered radiations, the detector shielding was designed in the form of a cylindrical lead collimator housing the detector as shown in Fig. 1. The diameter of the collimator was $3 \mathrm{~mm}$. The distances between the metal plate and the sample and between the sample and the detector were 70 and $89 \mathrm{~mm}$, respectively.

As an X-ray beam passes through a sample of thickness $\mathrm{X}$ $(\mathrm{cm})$, the intensity of the beam will be attenuated through the absorber according to the Beer-Lambert's law which is given by

$$
I=I o e_{-} \mu x
$$

where $I o$ refers to the photon intensity without attenuation; $I$ the photon intensity after attenuation. $\mu\left(\mathrm{cm} \_1\right)$ is the linear attenuation coefficient of the sample material. By rearranging the equation we get

$$
\mu=1 / \times \ln (I o / I)
$$

When the linear attenuation coefficient is divided by the density of the sample, we have the density independent mass attenuation coefficient $\mu / \rho(\mathrm{cm} 2 / \mathrm{g})$

$$
\mu=1 / \rho \times \ln (\operatorname{Io} / I)
$$

where $\rho x$ is the area density also known as the mass thickness.

Using Maestro software, the net area of intensity under the characteristic X-ray peak was analyzed and recorded as $I x$, where $x$ is the sample's thickness and the intensity without using any thickness was also recorded as Io. The same procedure was done for the GA and the twelve GA treated Rhizophora spp. particleboard samples (three particle sizes and four GA percentage levels) using the five different energies. Graphs of $\ln (I o / I x)$ against thickness were plotted for all samples. The linear attenuation coefficient is the slope of the curve. The mass attenuation coefficient of a particleboard was calculated by dividing the linear attenuation coefficient with the density.

Then, the results obtained in the present study were compared with the mass attenuation coefficient of water [9] calculated using XCOM computer software [10].

\section{RESUlTS AND DISCUSSION}

\section{A. Rhizophora spp. Particleboards}

The manufactured particleboards had very smooth surfaces and strong rigid texture. The results and specification of the fabricated particleboards are presented in Table I.

TABLE I: SUMMARY OF THE MANUFACTURED RHIZOPHORA SPP. PARTICLEBOARD SAMPLES BONDED WITH GUM ARABIC

\begin{tabular}{lll}
\hline Sample & Particle size $(\boldsymbol{\mu m})$ & Gum level $(\%)$ \\
\hline & & $0 \%$ \\
$\mathrm{~A}_{0}$ & & $5 \%$ \\
$\mathrm{~A}_{5}$ & & $10 \%$ \\
$\mathrm{~A}_{10}$ & $149-210$ & $15 \%$ \\
$\mathrm{~A}_{15}$ & & \\
$\mathrm{~B}_{0}$ & & $0 \%$ \\
$\mathrm{~B}_{5}$ & & $5 \%$ \\
$\mathrm{~B}_{10}$ & $74-149$ & $10 \%$ \\
$\mathrm{~B}_{15}$ & & $15 \%$ \\
$\mathrm{C}_{0}$ & & $0 \%$ \\
$\mathrm{C}_{5}$ & $<74$ & $5 \%$ \\
$\mathrm{C}_{10}$ & & $10 \%$ \\
$\mathrm{C}_{15}$ & & $15 \%$ \\
$\mathrm{Gum}$ & $<149$ & ----- \\
\hline
\end{tabular}

B. The Linear and Mass Attenuation Coefficients of GA and GA Bonded Rhizophora spp. Particleboards

The mass attenuation coefficients of the pure GA and the 
fabricated Rhizophora spp. particleboards were also determined in the photon energy range of $17.4-26.7 \mathrm{keV}$ by studying the attenuation of XRF photons from niobium, molybdenum, palladium, silver, and tin targets as presented in Table II. The incident and transmitted intensities of the detected beam were determined from the net counts under the $\mathrm{K}_{\alpha 1}$ peak of the XRF spectrum for the metal targets.

TABLE II: THE MEASURED LINEAR AND MASS ATTENUATION COEFFICIENTS OF RHIZOPHORA SPP. PARTICLEBOARD SAMPLES AND THE GuM ARABIC DEPENDING ON THE KA1 PEAKS OF THE CHARACTERISTIC X-RAY OF THE METAL TARGETS

\begin{tabular}{|c|c|c|c|c|}
\hline \multicolumn{5}{|c|}{$\mathrm{Ag}(17.4 \mathrm{keV})$} \\
\hline Sample & $\begin{array}{c}\text { Density, } \\
\left(\mathrm{g} / \mathrm{cm}^{3}\right) \\
\end{array}$ & $\begin{array}{l}\boldsymbol{\mu} \\
\left(\mathrm{cm}^{-1}\right) \\
\end{array}$ & $\begin{array}{l}\boldsymbol{\mu} / \boldsymbol{\rho} \\
\left(\mathrm{cm}^{2} / \mathrm{g}\right)\end{array}$ & $\begin{array}{l}\text { Error } \\
( \pm \%)\end{array}$ \\
\hline $\mathbf{A}_{0}$ & 1.075 & 1.148 & 1.068 & 0.005 \\
\hline $\mathbf{A}_{5}$ & 1.192 & 1.298 & 1.089 & 0.004 \\
\hline $\mathbf{A}_{10}$ & 1.049 & 1.15 & 1.096 & 0.023 \\
\hline $\mathbf{A}_{15}$ & 1.137 & 1.271 & 1.118 & 0.019 \\
\hline $\mathbf{B}_{0}$ & 1.134 & 0.649 & 1.005 & 0.01 \\
\hline $\mathbf{B}_{5}$ & 1.095 & 1.211 & 1.102 & 0.048 \\
\hline $\mathbf{B}_{10}$ & 1.131 & 1.226 & 1.083 & 0.036 \\
\hline $\mathbf{B}_{15}$ & 1.079 & 1.226 & 1.153 & 0.013 \\
\hline $\mathbf{C}_{0}$ & 1.062 & 1.156 & 1.089 & 0.006 \\
\hline $\mathrm{C}_{5}$ & 1.201 & 1.350 & 1.124 & 0.028 \\
\hline $\mathrm{C}_{10}$ & 1.144 & 1.252 & 1.094 & 0.053 \\
\hline $\mathrm{C}_{15}$ & 1.076 & 1.260 & 1.172 & 0.020 \\
\hline Gum & 1.351 & 1.913 & 1.416 & 0.011 \\
\hline \multicolumn{5}{|c|}{ Mo (18.5 keV) } \\
\hline $\mathbf{A}_{0}$ & 1.075 & 1.013 & 0.943 & 0.01 \\
\hline $\mathbf{A}_{5}$ & 1.192 & 1.017 & 0.854 & 0.106 \\
\hline $\mathbf{A}_{10}$ & 1.049 & 1.004 & 0.957 & 0.014 \\
\hline $\mathbf{A}_{15}$ & 1.137 & 1.116 & 0.981 & 0.104 \\
\hline $\mathbf{B}_{0}$ & 1.134 & 0.981 & 0.865 & 0.026 \\
\hline $\mathbf{B}_{5}$ & 1.095 & 1.053 & 0.962 & 0.004 \\
\hline $\mathbf{B}_{10}$ & 1.131 & 1.072 & 0.947 & 0.01 \\
\hline $\mathbf{B}_{15}$ & 1.079 & 1.023 & 0.948 & 0.022 \\
\hline $\mathrm{C}_{0}$ & 1.062 & 1.028 & 0.968 & 0.006 \\
\hline $\mathrm{C}_{5}$ & 1.201 & 1.179 & 0.981 & 0.026 \\
\hline $\mathrm{C}_{10}$ & 1.144 & $1 . .072$ & 0.937 & 0.015 \\
\hline $\mathrm{C}_{15}$ & 1.076 & 1.128 & 1.048 & 0.007 \\
\hline Gum & 1.351 & 1.803 & 1.335 & 0.061 \\
\hline \multicolumn{5}{|c|}{ Nb (22.4 keV) } \\
\hline $\mathbf{A}_{0}$ & 1.075 & 0.658 & 0.612 & 0.012 \\
\hline $\mathbf{A}_{5}$ & 1.192 & 0.721 & 0.618 & 0.035 \\
\hline $\mathbf{A}_{10}$ & 1.049 & 0.647 & 0.617 & 0.011 \\
\hline $\mathbf{A}_{15}$ & 1.137 & 0.693 & 0.609 & 0.033 \\
\hline $\mathbf{B}_{0}$ & 1.134 & 0.605 & 0.573 & 0.012 \\
\hline
\end{tabular}

\begin{tabular}{|c|c|c|c|c|}
\hline $\mathbf{B}_{5}$ & 1.095 & 0.705 & 0.644 & 0.009 \\
\hline $\mathbf{B}_{10}$ & 1.131 & 0.696 & 0.615 & 0.014 \\
\hline $\mathbf{B}_{15}$ & 1.079 & 0.676 & 0.636 & 0.009 \\
\hline $\mathrm{C}_{0}$ & 1.062 & 0.61 & 0.659 & 0.005 \\
\hline $\mathrm{C}_{5}$ & 1.201 & 0.764 & 0.636 & 0.016 \\
\hline $\mathrm{C}_{10}$ & 1.144 & 0.694 & 0.606 & 0.009 \\
\hline $\mathrm{C}_{15}$ & 1.076 & 0.728 & 0.677 & 0.006 \\
\hline Gum & 1.351 & 1.113 & 0.823 & 0.014 \\
\hline \multicolumn{5}{|c|}{ Pd (23.5 keV) } \\
\hline $\mathbf{A}_{0}$ & 1.075 & 0.581 & 0.54 & 0.070 \\
\hline $\mathbf{A}_{5}$ & 1.192 & 0.678 & 0.569 & 0.069 \\
\hline $\mathbf{A}_{10}$ & 1.049 & 0.599 & 0.571 & 0.036 \\
\hline $\mathbf{A}_{15}$ & 1.137 & 0.653 & 0.574 & 0.042 \\
\hline $\mathbf{B}_{0}$ & 1.134 & 0.604 & 0.532 & 0.066 \\
\hline $\mathbf{B}_{5}$ & 1.095 & 0.64 & 0.547 & 0.008 \\
\hline $\mathbf{B}_{10}$ & 1.131 & 0.622 & 0.55 & 0.010 \\
\hline $\mathbf{B}_{15}$ & 1.079 & 0.656 & 0.608 & 0.073 \\
\hline $\mathrm{C}_{0}$ & 1.062 & 0.610 & 0.574 & 0.004 \\
\hline $\mathrm{C}_{5}$ & 1.201 & 0.684 & 0.569 & 0.005 \\
\hline $\mathrm{C}_{10}$ & 1.144 & 0.627 & 0.548 & 0.023 \\
\hline $\mathrm{C}_{15}$ & 1.076 & 0.691 & 0.642 & 0.009 \\
\hline Gum & 1.351 & 0.941 & 0.697 & 0.040 \\
\hline \multicolumn{5}{|c|}{ Sn $(26.7 \mathrm{keV})$} \\
\hline$A_{0}$ & 1.075 & 0.484 & 0.45 & 0.012 \\
\hline $\mathbf{A}_{5}$ & 1.192 & 0.51 & 0.428 & 0.021 \\
\hline $\mathbf{A}_{10}$ & 1.049 & 0.473 & 0.451 & 0.019 \\
\hline $\mathbf{A}_{15}$ & 1.137 & 0.489 & 0.43 & 0.040 \\
\hline $\mathbf{B}_{0}$ & 1.134 & 0.490 & 0.432 & 0.005 \\
\hline $\mathbf{B}_{5}$ & 1.095 & 0.5 & 0.455 & 0.013 \\
\hline $\mathbf{B}_{10}$ & 1.131 & 0.509 & 0.449 & 0.005 \\
\hline $\mathbf{B}_{15}$ & 1.079 & 0.542 & 0.510 & 0.032 \\
\hline $\mathrm{C}_{0}$ & 1.062 & 0.45 & 0.424 & 0.019 \\
\hline $\mathrm{C}_{5}$ & 1.201 & 0.571 & 0.475 & 0.010 \\
\hline $\mathrm{C}_{10}$ & 1.144 & 0.505 & 0.441 & 0.033 \\
\hline $\mathrm{C}_{15}$ & 1.076 & 0.517 & 0.48 & 0.009 \\
\hline Gum & 1.351 & 0.764 & 0.565 & 0.029 \\
\hline
\end{tabular}

The mass attenuation coefficients of Rhizophora spp. from the counts under the $\mathrm{K}_{\alpha 1}$ XRF peaks of the different particleboard samples as compared with those of water calculated using XCOM were plotted as a graph in Fig. 2.

In the light of the graph above, it was concluded that the mass attenuation coefficient of Rhizophora spp. particleboards obtained by XRF technique at photon energies between $17.4-26.7 \mathrm{keV}$ were close to the values of water calculated in XCOM at the same photon energies. The mass attenuation coefficients of the Rhizophora spp. particleboards for the samples A5, B0, C0, C5, C10 and C15 
were close to the calculated value of water which is often considered as the perfect match for soft-tissue. Results of the present study agree with other researchers' findings who studied the suitability of Rhizophora spp. as a tissue equivalent material. For example, Bradley et al. [3] found that Rhizophora spp. wood has tissue-equivalent characteristics which could be consumed to develop a phantom material for radiation dosimetry applications. Rhizophora spp. wood was found to be similar to water in terms of both, mass-density and attenuation. In addition, Tajuddin et al. [4] found that Rhizophora spp. and modified rubber possess scattering and radiographic properties that are similar to water.

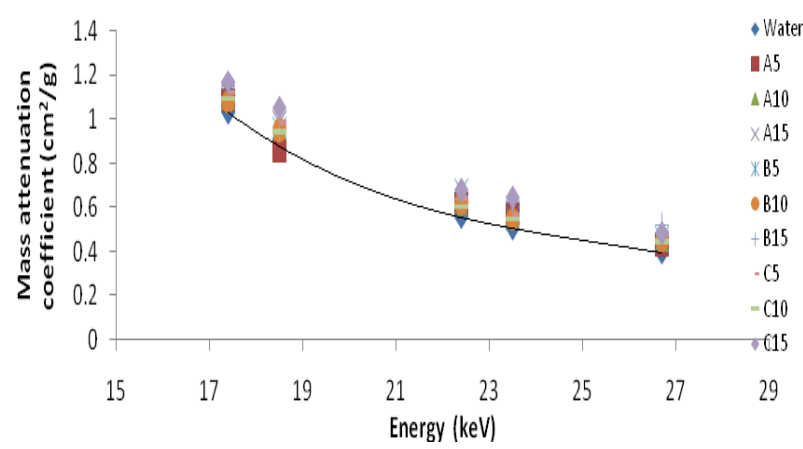

Fig. 2. Mass attenuation coefficients of Rhizophora spp. particleboards from the counts under the K $\alpha 1$ XRF peaks of the different samples as compared with water (calculated in XCOM).

However, B0 and C0 samples which were taken from binderless particleboards and pressed without gum also matched with water. This finding agrees with Marashdeh et al. [2], who indicated the significant attenuation properties of the binderless Rhizophora spp. particleboards.

In this study, gum was added to the particleboards to enhance their physical and mechanical properties and at the same time retain its attenuation properties. This aim was achieved and it was proved that the gum treated samples A5, $\mathrm{C} 5, \mathrm{C} 10$ and $\mathrm{C} 15$ have mass attenuation coefficients which are very close to water in the photon energy range of $15.77-25.27 \mathrm{keV}$.

\section{CONCLUSION}

Based on the results of this study, particleboards bonded with GA resulted in smoother surfaces and more rigid texture compared to binderless particleboards. The mass attenuation coefficients of Rhizophora spp. particleboards obtained by $\mathrm{XRF}$ technique at photon energies between $17.4-26.7 \mathrm{keV}$ were close to the values of water calculated in XCOM program at the same photon energies. GA bonded particleboards can be recommended to be used as tissue equivalent phantom material for dosimetric applications.

\section{ACKNOWLEDGMENT}

The authors would like to acknowledge the financial support of research university grant 1001/pfizik/846085 from Universiti Sains Malaysia.

\section{REFERENCES}

[1] Bibliography of Photon Total Cross-section (attenuation coefficient) Measurements $10 \mathrm{eV}$ to $13.5 \mathrm{GeV}$, US National Bureau of Standards NBSIR 86-3461, 1986

[2] M. W. Marashdeh, S. Bauk, A. A. Tajuddin, and R. Hashim, "Measurement of mass attenuation coefficients of Rhizophora spp. binderless particleboards in the 16.59-25.26 keV photon energy range and their density profile using x-ray computed tomography," Applied Radiation and Isotopes, vol. 70, issue 4, pp. 656-662, April 2012.

[3] D. A. Bradley, A. A. Tajuddin, C. W. A. C. W. Sudin, and S. Bauk, "Photon attenuation studies on tropical hardwoods," International Journal of Radiation Applications and Instrumentation-Part A Applied Radiation and Isotopes, vol. 42, issue 8, pp. 771-773, 1991.

[4] A. A. Tajuddin, C. W. A. C. W. Sudin, and D. A. Bradley, "Radiographic and scattering investigation on the suitability of Rhizophora sp. as tissue-equivalent medium for dosimetric study," Radiation Physics and Chemistry, vol. 47, issue 5, pp. 739-740, May 1996.

[5] D. P. Banjade, A. A. Tajuddin, and A. Shukri, "A study of Rhizophora spp wood phantom for dosimetric purposes using high energy photon and electron beams," Applied Radiation and Isotopes, vol. 55, issue 3 , pp. 297-302, Sep 2001

[6] S. Bauk and A. Z. Tajuddin, "Attenuation coefficients of Rhizophora spp. in the 11.22 to $28.43 \mathrm{keV}$ photon energy range," Journal of Nuclear and Related Technologies, vol. 5, no. 1, pp. 11-19, 2008.

[7] B. I. Surani, "The suitability of PF, UF, and PRF resins in terms of structure and attenuation properties to be used in Rhizophora spp. particleboard phantom," M. S. thesis, Universiti Sains Malaysia, Malaysia, 2008

[8] B. Z. Shakhreet, S. Bauk, A. A. Tajuddin, and A. Shukri, "Mass attenuation coefficients of natural Rhizophora spp. wood for X-rays in the 15.77-25.27 keV range," Journal of Radiation Protection Dosimetry, vol. 135, issue 1, pp. 47-53, July 2009.

[9] C. Constantinou, "Phantom materials for radiation dosimetry. I. Liquids and gels," The British Journal of Radiology, vol. 55, issue 651, pp. 217-224, March 1982.

[10] M. J. Berger and J. H. Hubbell, XCOM: Photon Cross Sections on a Personal Computer, US Department of Commerce, 1987, pp. 1-10.

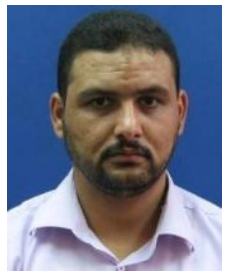

Ali Abuarra received his B.Sc. in medical imaging from Al-Quds University, Palestine. His master in medical physics was received from Universiti Sains Malaysia and he is currently doing his $\mathrm{Ph} . \mathrm{D}$. in the same institution. His research interests include particleboards manufacturing, radiation dosimetry, thermoluinescent dosimeters, Gafchromic films, and laser.

He has publications in several refereed international journals, in addition to conference proceedings and publications. 